\title{
Environmental impact assessment in the Apure River
}

\author{
Y. Takeuchi ${ }^{1}$, M. Takezawa ${ }^{2} \&$ H. Gotoh ${ }^{2}$ \\ ${ }^{1}$ Japan Infrastructure Partners, Japan \\ ${ }^{2}$ Civil Engineering, College of Science \& Technology, Nihon University, \\ Japan
}

\begin{abstract}
This study describes an environmental impact assessment conducted in conjunction with the Apure River Improvement Project in Venezuela. The study area consists of two very large sub-areas: a $20,000-\mathrm{km}^{2}$ area that is being studied with the objective of flood mitigation, and an area along $930 \mathrm{~km}$ of rivers that is being studied for navigation purposes. The study area is a vast and almost virgin region, barely reclaimed and sparsely inhabited, where the traffic is rare and environmental information is difficult to obtain. The total study period was restricted to 21 months, which was too short for a comprehensive environmental study, even one limited to reviewing available literature and cursory surveys in the field. We proposed an informal one-day workshop in an attempt to explore more efficient methods of collecting environmental information. The workshop was held as the first part of an infrastructure planning study by the Japan International Cooperation Agency.

Keywords: environmental impact assessment, flood mitigation, navigation, Apure River, Venezuela.
\end{abstract}

\section{Introduction}

We conducted a study on the comprehensive improvement of the Apure River in Venezuela [1] from March of 1992 to November of 1993. The study area covered a $680 \mathrm{~km}$ stretch of the main river, from the confluence with the Orinoco River to Guasdualito and a $250 \mathrm{~km}$ stretch of the Portuguesa River from San Fernand to El Baul, for navigation and a $20,000 \mathrm{~km}^{2}$ catchment area bounded by the Apure, the Masparro and the Portuguesa rivers for the study of flood 
mitigation as shown fig. 1 [1]. The study area is a vast territory consisting of almost virgin forest, barely reclaimed and sparsely inhabited, where the traffic is rare and environmental information is difficult to obtain. The total duration of the study was restricted to 21 months, which was too short to allow a comprehensive environmental study, even one based only on surveys of both the available literature and cursory surveys in the field. We proposed conducting a one-day workshop as a means of finding more efficient methods for collecting environmental information. The idea for a workshop was adopted, and the workshop was held as the first part of a master plan study by the Japan International Cooperation Agency (JICA). Attendees, consisting of 30 interdisciplinary experts in the fields such as ichthyology, ornithology, park, freshwater fisheries, ecology, aquatic fauna, agronomy, civil engineering, were divided into three groups, each of which consisted of a mixture of specialists in various fields [2]. In the environmental workshop, assessments were made on the interim results of flood mitigation and navigation studies from a variety of perspectives, and were not limited to those related only to environmental problems. Given the nature of the workshop and the aim of creating a general master plan based on the discussions that were convened, discussions were not particularly detailed and specific conclusions were not necessary. The results of the workshop should prove very useful for future feasibility studies.

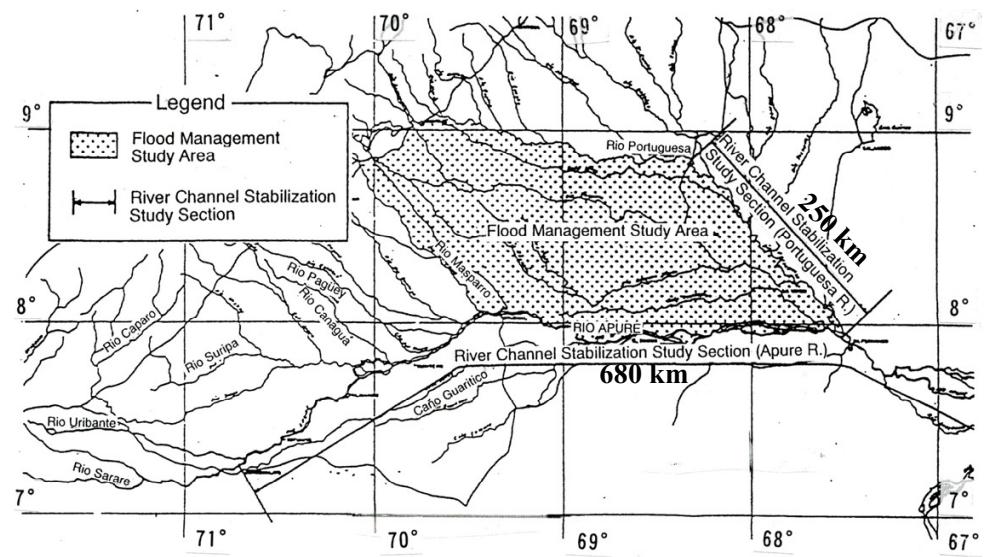

Figure 1: Area of the study on comprehensive improvement of the Apure River.

\section{Workshop}

The workshop was held at Laboratorio Nacional de Hidraulica, Ministerio de Ambiente y de los Recursos Naturales Renovables (MARNR), in Caracas from $08 \mathrm{~h} 00$ to $18 \mathrm{~h} 00$ on $5^{\text {th }}$ May 1993 [2]. The attendees at the workshop were requested to clarify the concepts of the project, to identify the environmental factors affected by the project, to discuss these based on their importance as well 
as their spatial and temporal characteristics and the time required for recovery of their current status, and to propose how to minimize the environmental impact of the project. The workshop was convened as part of a public awareness and consultative process to provide inhabitants with sufficient information and allow them to voice their opinions regarding the project.

The JICA established the Guidelines for the Environmental and Social Considerations to be used for river planning in September 1992 and revised these in April 2004. But the findings of the workshop were not included.

While four workshop groups were initially intended, attendees were divided into three groups on the day of the workshop. If the number of workshop attendees is too few, stimulating ideas is difficult and the objectivity of the workshop could be compromised by groups with relatively stronger opinions. Conversely, if too many attendees are present, some do not get the opportunity to voice their opinions and it is difficult to comprehensively summarize all of the opinions at the workshop. To balance these disadvantages, we divided the attendees into three groups for discussions and for summarizing their comments. The workshop itself was followed by a plenary session at which each group's comments were critiqued to frame them within an objective and rational synthesis [2].

We allocated specific field experts with task of presenting that group's comments objectively and to prevent each group from having markedly different comments from those of other groups. We assigned a chair to coordinate the meeting and to summarize the comments of the group representatives and assigned one secretary to each group. We also expected the lunchtime conversations to contribute positively to the total outputs from the workshop.

\section{Result of the workshop}

Comments were presented in the environmental workshop on a variety of aspects related to the interim results of the channel-stabilization and flood-control studies currently underway, not only the environmental problems. The discussions were cursory and were not concluded because of the nature of the workshop. Findings were classified based on the method presented below [3].

\subsection{Comments on environmental study}

E01. The communities that live along the rivers have specialized system for life support, based on a mixture of farming, ranching and fisheries; activities that would be affected by river works. Other sensitive human activities are the local subsistence or commercial fisheries, the new Apure Viejo National Park, local communities, cattle ranch associations and cotton growers.

E02. Diversion channels must be well studied given their influence on the landowners downstream.

E03. In instances of river channel alteration, specific ecological problems must be assessed by anticipating areas necessary for study. 
E04. River dredging would affect aquatic fauna in general, and the food sources of the commercial catfish in particular. To promote navigation of the natural channel, it should be restricted to specific or localized areas, adapting the vessels to the natural characteristics of channel width and water level throughout the year. Deposition of natural sediments has to be evaluated. The sediment transported from the higher river reaches of the watershed should be investigated and the flood mitigation measures that consider these characteristics should be designed and implemented.

E05. The influence of dam control on river navigation is expected to be negligible. The effect of altering the hydraulic regime of the river is expected to have a potential impact on aquatic fauna. If the adjusted flow of the river by current users permits alternately the use of existing dams for irrigation and hydroelectricity, it must not be compromised with new or additional uses by these dams.

E06. Alteration of the Caparo River channel is not compatible with the aims of the recently promulgated "Rio Apure Viejo" National Park. This national Park has only very recently been established after a declaration by the Minister of MARNR.

E07. Most of the work on dikes will affect the gallery forests along the rivers and the Paspalum grass savannas that are used locally by cattle.

E08. The effects of dikes on ecosystems tend to be large.

E09. Cattle ranching and other local wild life resource management could be negatively affected.

E10. Within the context of ecotourism, the new navigation system will permit access to locations that are currently inaccessible. However, the proposed activities could change the landscape and local distribution of wildlife and therefore endanger the natural resources of this increasingly important economic activity, decreasing the natural potential of certain areas.

E11. The protected environmental areas are also sensitive. There are two refuges and one new national park in the area.

E12. We should identify the potential impact of the following activities associated with development in the area: changes in sedimentation regime, water quality, riverine topography, river pollution, all of which have had negative effects on riverine fauna and flora, filling-in of anabranches with the consequential changes in habitat for some species and the acceleration of currents making it difficult or impossible for some fish species to migrate and, particularly, to complete their reproductive cycle.

E13. We proposed the following measures to mitigate against the environmental impacts associated with the works: consulting the affected communities, reforestation of the riverine forest, constant monitoring of water quality of physicochemical water parameters, establishing strict legal guidelines for construction works, planned and controlled territorial occupation and provision of basic services, avoiding canalization of the Cojedes River as this would affect one of the few natural populations of the endangered Orinoco Crocodile. 
E14. It is necessary to make environmental impact studies for several local productive animal species such as crocodile and cattle.

E15. Workshops directed at the different population segments must be prepared in order to establish their needs and desires so that these can be incorporated into the project.

E16. Gallery forests must be studied within the context of the environmental impact associated with possible flooding when a given river section has two dikes.

E17. Detailed studies of the fauna and flora of the Apure River and the Portuguesa River are necessary.

\subsection{Comments on channel stabilization study}

S01. Same as for comment E01.

S02. Same as for comment E02.

S03. The closure of anabranches does not need to be permanent and a method should be developed for regulating such areas during the dry season.

S04. Regarding the management of dams or reservoirs, this should develop from an integrated management corresponding to the observed environmental changes.

S05. Same as for comment E04.

S06. Same as for comment E05.

S07. Diversion channels risk high construction costs and no potential benefits for navigation. Again, the river should be used by adapting to natural conditions where possible.

S08. Same as for comment E06.

S09. The construction activities required for coffering of anabranches must permit minimal water discharge to the maintain navigation channel with simple structures that should function without human intervention. The effects of such structures should be evaluated.

S10. The Vega Honda Dam contracted to CIDIAT in 1991 did not meet the requirements of an economical feasibility analysis undertaken by MARNR.

S11. Fishing is negatively impacted by the channel stabilization works, because fish populations may become diminished due to disruptions to eggs and young fishes due to sedimentation, dredging, construction of diversion channels, and they may also migrate form the area.

S12. Same as for comment E10.

S13. Same as for comment E12.

S14. We identified the following positive aspects: more agricultural land, equilibrium with respect to national trends in land occupation, improved transportation and commerce, improved socio-economic conditions, provision of navigation facilities for small vessels.

S15. Same as for comment E13.

\subsection{Comments on the flood mitigation study}

F01. Same as for comment E01.

F02. Same as for comment E02. 
F03. Same as for comment S04.

F04. Protection of specific sites and areas from floods is not necessary because they are not located on good agricultural land. One group was of the opinion that Area $\mathrm{C}$ does not need dikes or flood control measures. The western region extending from Chiriguare to Troncal 5 does also not require general flood control mechanisms either. It is necessary to carefully study the social and economic convenience of protecting Area $\mathrm{C}$.

F05. Both options of having dikes on the right margins of the Portuguesa and the Cano Igues were studied briefly. Based on our analysis, we suggest eliminating the possibility of the alternative dike at the Cano Igues given that would only marginally benefit poor agricultural lands. The right dike of the Portuguesa must be carefully studied as it may affect Turen.

F06. The construction of a dike on the left bank of the Apure River does not seem feasible as it would negatively affect the discharge and deposition, as well as promote sedimentation in the channel. In addition, it might form shallow waters.

F07. In the case of the Portuguesa River, the dike would improve drainage from the Turen irrigation area, especially by the Cano El Frasco.

F08. Same as for comment S10.

F09. Same as for comment E07.

F10. Same as for comment E08.

F11. The construction of dikes over large expanses of land is probably not justified given that much of the land has no significant agricultural value. However, these areas have considerable potential if they are applied to uses that are compatible with their extant situation of being inundated.

F12. The construction of dikes should be only employed to protect existing agricultural developments or populated areas.

F13. The marginal soils of the Llanos lowlands do not require protection from flooding as they can be utilized by specifically adapted production systems, including buffalo, local fauna, fish, cattle grazing and tourism.

F14. Alternatives modules were proposed for the lower Llanos, suggesting that they not be incorporated into larger projects. Rather, their level of implementation should be at the relatively small, local cooperative or private endeavors, considering the experiences gained through the Apure Modules.

The Apure Modules, shown fig. 2 [1], are one of the land use modes employed in the inundated areas during the rainy season. The road meshed network used for evacuating cows during the rainy season and to water cows from the earth pits formed by the roads in the dry season.

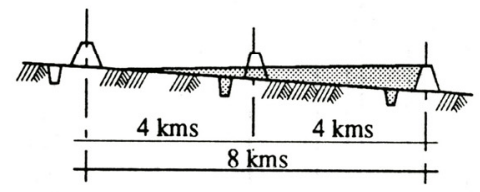

Rainy Season

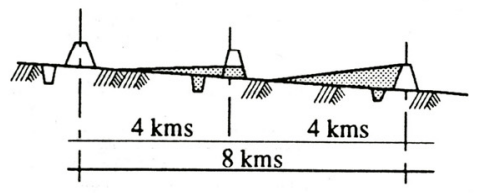

Dry Season

Figure 2: $\quad$ Apure modules. 
F15. Same as for comment S11.

F16. Same as for comment E11.

F17. Same as for comment E12.

F18. Same as for comment S14

F19. Same as for comment El3

F20. Same as for comment E16.

F21. For the flood plan, most issues were concerned with the construction of long dikes, favoring smaller segments for the protection of established agricultural lands and communities, and with the over riding need to develop more site- specific initiatives. These considerations are important because they allow for the implementation of protection measures when and where necessary, and also permit normal inundation where necessary.

\subsection{Comments on the navigation plan}

N01. One of the interesting observations regarding the development of a navigation plan was that mapping the navigational obstacles for vessels of certain sizes for different months revealed that individual obstacles had to be considered when navigating the river for extended periods. In this case, the recommendation was why they did not design a vessel that would be better adapted to the present conditions of the river instead of designing the river for a particular vessel. A vessel adapted to actual river conditions would be one measure that, if adopted, would help avoid the need for dredging or other engineering measures.

N02. The navigation project should be considered as part of a comprehensive management plan of the entire watershed.

N03. There is no alternative study of, for example, the navigation up to Bruzual and from there on to the upper reach by train.

N04. It would be advantageous to undertake a project for the design of shallower vessels that were capable navigating the river for more extended periods of the year.

N05. A cost-benefit analysis for the optimal navigation strategy has not yet been undertaken.

N06. Studies must be conducted for smaller vessels that would cause less disturbance when used on the river.

N07. A study on alternative transportation options increases the likelihood of competition, which encourages lower prices in certain goods and so on.

N08. 0ther aspects requiring attention are the influence of river transport on the cost structure of agricultural production, human population movements, basic aspects of fecundity, diet and physiological items of economically important species.

N09. Another important issue is the recommendation for a new, feasible river plan that considers simpler and more natural ways to navigate the river causing considerably less environmental impact. 


\subsection{Additional comments}

O01. A strategy involving continuous consultation with the local communities should be pursued.

O02. Local land use must be assessed to determine to what extent rice and pastures can be cultivated without dikes.

O03. Sedimentation studies formerly conducted by the Division of Hydrology should be continued, as they seem to have been discontinued. A new study of sediment in the upper river reaches is necessary.

O04. The MARNR should consider other alternatives to navigation in order to attain the objective of a more spatially varied land use and a better distribution of the population. One such alternative with considerable potential was to extend the benefits of the extant welfare system for the local populations by improving facilities related to health, medical care, school, access to food, agricultural techniques, among others.

O05. Priority should be given to the formulation of a basic research plan within a global or master plan.

O06. Diversification of land use by harvesting a variety of local animal and vegetable resources is considered preferable to monoculture.

O07. Dams along the Guanare and the Portuguesa rivers, the Puente Tejera Dam and the Vega Honda Dam, have all been found not to be feasible, as they have not met the demands of flood mitigation and navigation. Instead, they have promoted sedimentation in their reservoirs, which in turn has resulted in environmental degradation in their basin.

O08. Instead of building new dikes, MARNR should concentrate on consolidating the areas that have agricultural development potential, such as the Guanare, the Masparro and the Turen basins.

O09. While increasing the amount of land available for agricultural development seems appropriate, studies must be conducted to assess the potential of designated beforehand.

O10. Local populations can be negatively affected if local and indigenous people are not provided with access to appropriate conditions.

O11. Plans for regional development must be implemented, as well as an economic and social studies of the products from the area and their potential markets.

O12. A plan needs to be developed to explain the projects in a timely manner to all interested and affected parties within the area.

O13. MARNR needs to reaffirm its objectives and strategies for an increase in population along the Orinoco Apure Axis.

O14. Several fundamental issues emerged from the discussion tables, notably the emphasis placed by MARNR, which was criticized for focusing almost exclusively on river navigation as the primary means of enhancing life in the area of influence.

Most attendants were of the opinion that MARNR should diversify the ways in which welfare is provided to the people within the area. This brought about the need for a Master Plan with broader considerations of the needs of the local inhabitants. 


\section{Review of the workshop}

There were several inappropriate comments related to several aspects of the river engineering, one of which was that the protection from flood of certain specific sites and areas were not necessary. However, the agripreneur was badly developed in the area and, with the exception of land use in the conservation area and protected wild life sanctuary, no land-use plans existed for other parts of the study area. Below we evaluate the merits and demerits of the workshop.

\subsection{Merits}

We were able to collect considerable and extensive interdisciplinary information within a short period.

We managed to assemble interdisciplinary experts at one conference and collect a wide variety of information that finally resulted in the formulation of objective and reasonable recommendations.

Comments were obtained from both national and regional planning and transportation networks.

It provided attendees to express opinions that may not have been possible otherwise. For example, engineers were able to explore alterations to the size of vessels as opposed to the river channels. In addition, we were able to recognize the importance of the study to attendees who were not members of the JICA study team.

Matters for consideration in successive studies became clear.

In the preliminary plan, we modified the right-side dike project, advocating a new study employing ring-dikes.

The workshop was widely reported in the local newspaper media.

\subsection{Demerits}

The short duration of the workshop meant that some interdisciplinary experts did not understand the objectives of project or each other.

The discussions were susceptible to loss of focus.

Documents from the workshop were given to members of the mass media and foreign environmental bodies who portrayed the exercise negatively. Their interpretation was that Japan needed wood material and was planning to open a new navigation channel for the transportation of harvested wood so that it could be exported to Japan. The International Rivers Network sent a letter registering their dissatisfaction with the project to the president of JICA.

We were not able explain some disputes that arose as a consequence of convening the workshop.

Some discussions were not logical and were emotional.

We supposed that the workshop did not succeed in assuring the regional inhabitants, resulting in misunderstanding. 


\section{Gentle works for less environment impact}

We were currently planning to undertake work on small scale that will have a low impact on the environment as well as low associated construction costs, the need for which was confirmed by the workshop. We did not explore the idea of scaling down the project by investigating the potential of changing the shape and size of cargo vessels to decrease environmental impact. Despite the potential importance of this idea, the duration and costs of the workshop prevented further investigation into the potential of this suggestion, which we believe should be studied hereafter. We describe gentle works for less environment impact for planning environmental initiatives as follows:

\subsection{Flood mitigation activities}

For considerations of flooding, the study area was in an almost natural state and the recommendations of the workshop are likely to be sufficient for environmental impacts associated with the project. We selected gentler works for less environment impact if they were more economically efficient and include the following features shown in fig. 3 [1].

1) one-sided dikes;

2) ring dikes;

3) non-dikes at a confluence for retarding basin;

4) dike combined with existing road.

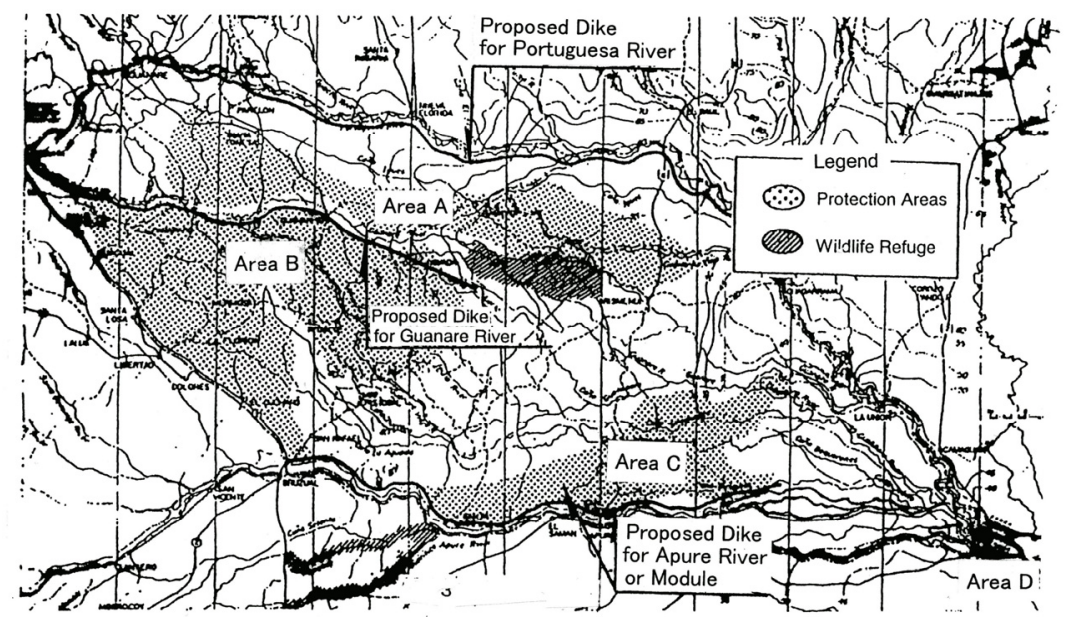

Figure 3: $\quad$ Flood mitigation plan in the Apure River Basin.

Where possible, use of the following was discouraged:

1) dams;

2) continuous dikes on both sides of the river;

3) enlargement of discharge section by felling trees along natural dikes

(and we designed all the new dikes to use combined dikes with new roads). 


\subsection{Navigation activities}

There are two methods conventionally employed for navigating a standard cargo vessel on a river. One is to increase the discharge in the river channel and the other is to stabilize the river channel. We selected gentler works for less environment impact for the environment as following shown fig. 4 [1].

1) removing and merging existing channels to increase discharge in the channel;

2) submerged weirs for regulating the discharge into anabranches;

3) permeable groins for to stabilizing channel beds.

We avoided the more severe engineering works for enlarging the river channel where possible. Such methods include the following:

1) large-scale dredging;

2) the use of locks and dikes.

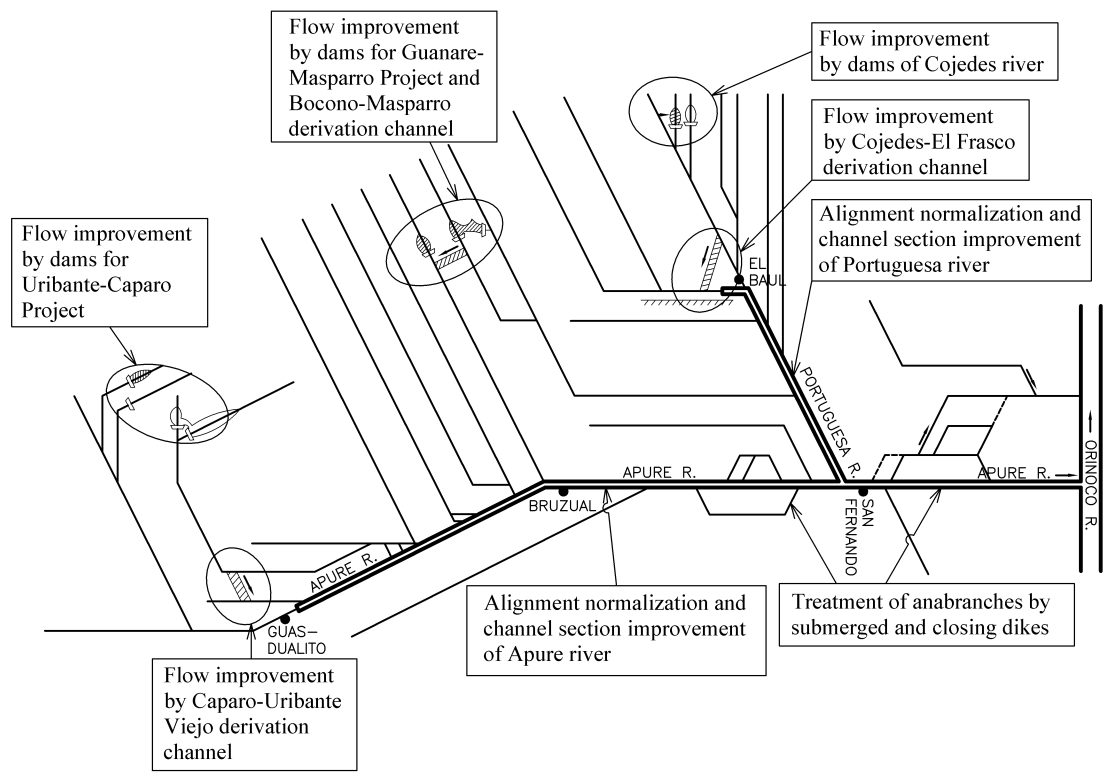

Figure 4: Navigation plan on the Apure River.

\section{Conclusion}

We found the medium of this environmental workshop considerably useful for conducting environmental impact assessments at a master plan level and for obtaining an outline suitable for short-term implementation for 7 or 9 years when the amount of data is limited in a large study field. Workshops also offer local 
inhabitants a valuable opportunity to engage in public discourse and the exchange of information, which can then be disseminated by newspapers.

The results of this workshop are useful for the development of large-scale, master-plan type transportation and economic assessments of navigation potential and for use as a feasibility study of flood mitigation projects.

If it were possible to convene a second workshop a week or a month after the workshop described here, then it is highly likely that the comments of attendees would be more consolidated.

\section{Acknowledgements}

The authors express their sincere gratitude to the members of JICA and the attendees at the workshop in this study.

\section{References}

[1] Japan International Cooperation Agency, Study on Comprehensive Improvement of the Apure River Basin, pp. 1-4, F. 1, F.7, F. 18, F. 29, Final report volume I, Tokyo, 1993.

[2] Japan International Cooperation Agency, Study on Comprehensive Improvement of the Apure River Basin, EF. 50, EF.62, pp. I.3.1.-16, I.4.1.-3, Final report volume III, Tokyo, 1993.

[3] Japan International Cooperation Agency, Study on Comprehensive Improvement of the Apure River Basin, Short hand notes, Caracas, 1993. 